\title{
Synthesis and structure of analcime and analcime-zirconia composite derived from coal fly ash cenospheres
}

\author{
Tatiana A. Vereshchagina ${ }^{a,}{ }^{*}$, Ekaterina A. Kutikhina ${ }^{a}$, Leonid A. Solovyov ${ }^{\text {, }}$ \\ Sergei N. Vereshchagin a , Elena V. Mazurova ${ }^{a}$, Yana Yu. Chernykh ${ }^{a}$, \\ Alexander G. Anshits a, b \\ a Institute of Chemistry and Chemical Technology SB RAS, Federal Research Center "Krasnoyarsk Science Center SB RAS", 50/24 Akademgorodok, \\ Krasnoyarsk, 660036, Russia \\ b Department of Chemistry, Siberian Federal University, Svobodny pr. 79, Krasnoyarsk, 660041, Russia
}

\section{A R T I C L E I N F O}

\section{Article history:}

Received 24 May 2017

Received in revised form

23 August 2017

Accepted 12 September 2017

Available online 18 September 2017

\section{Keywords:}

Analcime

Cenospheres

Zirconia

Hydrothermal synthesis

\begin{abstract}
A B S T R A C T
Cubic analcime and analcime-zirconia composite with the Si/Al ratio of 2.04 and 2.16, respectively, was synthesized by hydrothermal treatment of coal fly ash cenospheres $(\mathrm{Si} / \mathrm{Al}=2.7)$ at $150^{\circ} \mathrm{C}$. The scanning electron microscopy with energy dispersive spectroscopy (SEM-EDS), powder X-ray diffraction (PXRD), X-ray photoelectron spectroscopy (XPS), synchronous thermal analysis (STA) methods were used to study the morphology, composition and structure of the products. Two main types of analcime bearing particles were obtained, such as hollow microspheres with attached analcime icositetrahedra of 5 $-50 \mu \mathrm{m}$ in size and individual analcime crystals of a narrow particle size distribution $\left(\mathrm{D}_{\mathrm{m}}=41 \mu \mathrm{m}\right)$ with incorporated zirconia ( $4.8 \mathrm{wt} \% \mathrm{Zr}$ ). The high quality of the crystalline fractions allowed an accurate fullprofile PXRD analysis of complete analcime crystal structure and composition including anisotropic displacement parameters of all atoms and $\mathrm{H}$-positions of water molecules.
\end{abstract}

๑) 2017 Elsevier Inc. All rights reserved.

\section{Introduction}

Analcime (ANA) is a natural occurring zeolite with a tetragontrioctahedron habit which has a typical unit cell composition of $\mathrm{Na}_{16}\left[\left(\mathrm{AlO}_{2}\right)_{16}\left(\mathrm{SiO}_{2}\right)_{32}\right] \cdot 16 \mathrm{H}_{2} \mathrm{O}$ with a $\mathrm{Si} / \mathrm{Al}$ molar ratio of $1.8-2.8$ $[1,2]$. For its synthetic analogs the $\mathrm{Si} / \mathrm{Al}$ ratio varies in a more wide range (1.5-3.0) depending on the cation nature, $\mathrm{Si}$ and $\mathrm{Al}$ sources, and conditions of synthesis [3]. Analcime has a 3-dimensional system of non-intersecting channels with the pore openings of $2.6 \AA$ composed of four-, six- and eight-membered oxygen rings. High symmetry icositetrahedral morphology of analcime crystals is attractive for designing novel materials of a regular polyhedron form [4-6].

Due to minimal pore entrances compared to other zeolites, analcime is useful in separation of light gas/hydrocarbon mixtures, e.g. $\mathrm{H}_{2} / \mathrm{C}_{3} \mathrm{H}_{8}$, based on the molecular sieving effect [7]. Synthetic

\footnotetext{
* Corresponding author.

E-mail addresses: tatiana_ver@mail.ru (T.A. Vereshchagina), ekaterina_ kutikhina@mail.ru (E.A. Kutikhina), leosol@icct.ru (L.A. Solovyov), snv@icct.ru (S.N. Vereshchagin), len.mazurowa@yandex.ru (E.V. Mazurova), yaninachernyh@ yandex.ru (Y.Yu. Chernykh), anshits@icct.ru (A.G. Anshits).
}

analcimes, pure and metal ( $\mathrm{Mn}, \mathrm{Ti}, \mathrm{V})$ modified in T-positions, are efficient in a heterogeneous catalysis, e. g. cyclohexene oxidation in a liquid phase [8], and an ion exchange for removal of heavy metals from wastewater [9]. Analcime is the object of some studies in relation to the problem of nuclear waste disposal [10-14]. This narrow-pore zeolite can be used in nuclear waste burial as a sorptive barrier for radioactive elements because of its ability to bind actinide cations $\left(\mathrm{U}^{4+}, \mathrm{Th}^{4+}\right)$ by sorption irreversibly providing the reliable immobilization of toxic metals [10]. The similarity of framework topology of analcime and pollucite, $\left(\mathrm{Cs}_{1-n}, \mathrm{Na}_{n}\right)\left(\mathrm{H}_{2} \mathrm{O}\right)-$ ${ }_{n}\left[\mathrm{AlSi}_{2} \mathrm{O}_{6}\right]$ [2], is the basis of methods for incorporation of radioactive ${ }^{137} \mathrm{Cs}$ in ANA phases resulting in pollucite or polluciteanalcime solid solutions [11-14].

Numerous studies are concerned with transition metal modified (exchanged/impregnated) zeolites as precursors of aluminosilicatebased ceramics including electronic ceramics [15] and ceramic bodies for electromagnetic shielding [16]. Zr bearing zeolites are of particular interest because they can be converted to refractory zirconia-aluminosilicate ceramic materials [17] having a potential as a chemically stable radioactive waste form [18]. Two kinds of $\mathrm{Zr}$ bearing zeolite precursors can be considered, such as zeolites modified at an atomic level by $\mathrm{Zr}^{4+}$ incorporation in T-sites or 
cation positions, and zeolite based composites with $\mathrm{Zr}$ bearing matter embedded in the zeolite body. As for the analcime based precursor, the incorporation of large $\mathrm{Zr}$ atoms $(\mathrm{R}=0,72 \AA)$ in the dense analcime lattice and extra-framework positions is hardly probable due to the restrictions of bond lengths [1]. The $\mathrm{Zr}$ incorporation in the analcime body as a $\mathrm{Zr}$ bearing matter has not been reported yet.

Traditionally hydrothermal methods are applied to synthesize zeolites of different topologies starting from alkaline solution of pure chemicals (e.g. sodium silicate, sodium aluminate) [19]. As it was reported by Fang et al. [5], the lower rate of glass dissolution compared to that of gel or fine chemicals provides large analcime crystallites of up to $600 \mu \mathrm{m}$ by hydrothermal treatment of sodium aluminosilicate glass at $150-210^{\circ} \mathrm{C}$.

The cost-effective synthetic routes to analcime are based on conversion of available natural and technogenic raw materials, such as clay minerals $(\mathrm{Si} / \mathrm{Al}=1.4)[8]$, coal fly ash $(\mathrm{Si} / \mathrm{Al}=1.6)[20]$, natural clinker $(\mathrm{Si} / \mathrm{Al}=2.5-3.0)[21]$, quartz syenite $(\mathrm{Si} / \mathrm{Al}=3.7)$ [22], and volcanic glass perlite $(\mathrm{Si} / \mathrm{Al}=4.6)[23]$. However, most of the sources didn't provide a high purity of the analcime product containing the additional zeolite phases (GIS, CAN, FAU, etc.).

Recently, coal fly ash cenospheres (CFAC) were considered for synthesis of low-siliceous zeolites without seeding and templating as an alternative aluminosilicate source of the sphere shaped morphology and glassy structure with the appropriate silicaalumina composition $(\mathrm{Si} / \mathrm{Al}=1.1-2.9)[24-26]$. The CFAC properties have been found to be suitable for their use as a template core and $\mathrm{Si}$ and $\mathrm{Al}$ source in the zeolite synthesis. The advantage of this approach is possibility to use CFAC of required chemical and phase composition provided by separation of a CFAC concentrate on the basis of differences of individual globules in size, density, and magnetic properties [27-29]. In most cases the direct transformation of the CFAC material, in dependence on reaction parameters (temperature, duration, alkaline concentration, solid-toliquid ratio), results in zeolitic phases of different structural types, such as NaX (FAU, JCPDS 12-0228), NaA (LTA, JCPDS 43-0142), NaP1 (GIS, JCPDS 40-1464), chabazite (CHA, JCPDS 12-0194), analcime (ANA, JCPDS 19-1180), and/or hydroxysodalite (JCPDS 11-401) [25]. Among them, only zeolite NaP1 was shown to crystallize as an individual phase under certain conditions $\left(\mathrm{T}=100-120^{\circ} \mathrm{C}, 1.5-2.5 \mathrm{M} \mathrm{NaOH}\right)[25,26]$. As it has been noted by Vereshchagin et al. [25], analcime crystallized at elevated temperatures $\left(\mathrm{T}>150{ }^{\circ} \mathrm{C}\right)$ but detailed results on zeolite formation from $\mathrm{CFAC}$ under temperatures higher than $120^{\circ} \mathrm{C}$ were not reported anywhere.

In this paper, we report the hydrothermal synthesis of analcime and zirconia bearing analcime at $150^{\circ} \mathrm{C}$ starting from CFAC with Si/ $\mathrm{Al}=2.7$, characterization of their structure, composition and morphology by PXRD, SEM-EDS, XPS and STA.

\section{Experimental}

\subsection{Chemicals and materials}

Chemicals used in this work were of reagent grade quality obtained from the commercial supplier (OOO "Reactiv", Russia) and used without further purification.

The CFAC material used for the analcime synthesis was fraction $-180+80 \mu \mathrm{m}$ having a bulk weight of $0.38 \mathrm{~g} \mathrm{~cm}^{-3}$ and a specific surface area of $0.2 \mathrm{~m}^{2} \mathrm{~g}^{-1}$ which was provided by the separation procedure of a CFAC concentrate resulted from combustion of Kuznetsk coal (Russia) at Tom-Usinskaya power plant (Kemerovo region, Russia) as it was reported earlier [27]. Chemical and mineral compositions of the initial CFAC material are summarized in Table 1. A total overview of the CFAC globules is shown in Fig. 1.

\subsection{Synthetic procedures}

Analcime was synthesized by hydrothermal treatment of a reaction mixture comprising of $10 \mathrm{~g}$ CFAC and $133 \mathrm{~mL} 1.5 \mathrm{M} \mathrm{NaOH}$ with $1.0 \mathrm{SiO}_{2} / 0.18 \mathrm{Al}_{2} \mathrm{O}_{3} / 0.89 \mathrm{Na}_{2} \mathrm{O} / 65 \mathrm{H}_{2} \mathrm{O}$ molar composition and liquid-to-solid $(\mathrm{L} / \mathrm{S})$ ratio of $5 / 1(\mathrm{v} / \mathrm{v})$. The reaction mixture was crystallized in a Teflon-lined stainless steel autoclave at $150{ }^{\circ} \mathrm{C}$ for $68 \mathrm{~h}$ under stirring by rotation of the autoclave (30 rpm). The grey solid phase (GS) was then washed several times with distilled water, filtered and dried at $65{ }^{\circ} \mathrm{C}$ for $24 \mathrm{~h}$. The output of the solid calculated relative to the mass of initial CFAC was $81 \%$. The subsequent separation of the GS product by particle sizes was done using sieves with apertures of $36 \mu \mathrm{m}, 71 \mu \mathrm{m}, 100 \mu \mathrm{m}$ and $224 \mu \mathrm{m}$. Samples GS $>224 \mu \mathrm{m}$, GS 100-224 $\mu \mathrm{m}$, GS 71-100 $\mu \mathrm{m}$, GS 36-71 $\mu \mathrm{m}$ and GS $<36 \mu \mathrm{m}$ were isolated by sieving the GS product with yields of $1.4,49.0,18.9,28.5$ and $2.2 \%$, respectively.

Zirconia bearing analcime was synthesized by hydrothermal treatment of CFAC in sodium alkaline solution in the presence of zirconium (IV) citrate ammonium complex used as a $\mathrm{Zr}$ source. In a typical synthesis, $5 \mathrm{~g}$ zirconium (IV) citrate ammonium complex was added to $133 \mathrm{~mL} 1.5 \mathrm{M} \mathrm{NaOH}$ solution upon stirring at room temperature followed by addition of $10 \mathrm{~g}$ CFAC resulting in the reaction mixture of $1.0 \mathrm{SiO}_{2} / 0.18 \mathrm{Al}_{2} \mathrm{O}_{3} / 0.89 \mathrm{Na}_{2} \mathrm{O} / 0.15 \mathrm{ZrO}_{2} / 65 \mathrm{H}_{2} \mathrm{O}$ molar composition with $\mathrm{L} / \mathrm{S}$ ratio of $5 / 1(\mathrm{v} / \mathrm{v})$. The mixture was transferred into the Teflon-lined stainless steel autoclave for crystallization by heating the suspension at $150{ }^{\circ} \mathrm{C}$ for $48 \mathrm{~h}$ under stirring by rotation of the autoclave ( $30 \mathrm{rpm})$. The white-and-grey solid (Zr-WGS) product was separated by filtration, washed with distilled water several times until neutral reaction of a supernatant occurred followed by centrifuging the suspension. Two layers were visually identified in centrifuge test tubes as white (Zr-WS) and grey (Zr-GS) solids, each of which was recovered and then dried at $65^{\circ} \mathrm{C}$ for $24 \mathrm{~h}$. The outputs of the $\mathrm{Zr}$-WS and $\mathrm{Zr}-\mathrm{GS}$ solids calculated relatively the mass of initial CFAC was 32 and $10 \%$, accordingly. Each layer was additionally separated into fractions by particle sizes using sieves with apertures of $36 \mu \mathrm{m}$ and $71 \mu \mathrm{m}$ resulting in samples $\mathrm{Zr}-\mathrm{WS}<36 \mu \mathrm{m}, \mathrm{Zr}-\mathrm{WS} 36-71 \mu \mathrm{m}$ with yields of 29 and $71 \%$, respectively, and $\mathrm{Zr}-\mathrm{GS}>71 \mu \mathrm{m}, \mathrm{Zr}-\mathrm{GS}<36 \mu \mathrm{m}$ with yields of 97 and $3 \%$, respectively.

\subsection{Characterization techniques}

Chemical composition of CFAC fraction was determined according to State Standard (GOST) No. 5382-91 [30].

Powder X-ray diffraction data were collected on a PANalytical X'Pert PRO (Netherlands) diffractometer equipped with a solid state detector PIXcel using $\mathrm{Cu} \mathrm{K} \alpha$ radiation over the $2 \theta$ range $12-120^{\circ}$. The samples were prepared by grinding with octane in an agate mortar and packed into a flat sample holder for the PXRD measurements in the Bragg-Brentano geometry. The full-profile crystal structure analysis was done using the Rietveld method [31] with the derivative difference minimization (DDM) [32] refinement.

Morphologies of product particles were identified by scanning electron microscopy (SEM) using TM-1000 and TM-3000 (Hitachi, Japan) instruments. To study elemental composition of surfaces and polished sections of analcime particles the SEM-EDS examination was performed using the TM-3000 microscope equipped with the Bruker microanalysis system including an energy-dispersive X-ray spectrometer with a XFlash $430 \mathrm{H}$ detector and QUANTAX 70 software. The polished sections of analcime particles were prepared by fixing in an epoxy resin with successive grinding and polishing with the use of STRUERS materials and equipment 
Table 1

Chemical and mineral composition (wt\%) of the initial CFAC material.

\begin{tabular}{|c|c|c|c|c|c|c|c|c|c|c|c|c|}
\hline \multicolumn{8}{|c|}{ Elements in terms of oxides } & \multirow[t]{2}{*}{$\mathrm{Si} / \mathrm{Al}$} & \multicolumn{3}{|c|}{ Crystal phases } & \multirow[t]{2}{*}{ Glass phase } \\
\hline $\mathrm{SiO}_{2}$ & $\mathrm{Al}_{2} \mathrm{O}_{3}$ & $\mathrm{Fe}_{2} \mathrm{O}_{3}$ & $\mathrm{Na}_{2} \mathrm{O}$ & $\mathrm{CaO}$ & $\mathrm{MgO}$ & $\mathrm{K}_{2} \mathrm{O}$ & $\mathrm{TiO}_{2}$ & & quartz & mullite & calcite & \\
\hline 67.6 & 21.0 & 3.0 & 0.9 & 2.2 & 1.8 & 2.8 & 0.2 & 2.7 & 3.4 & 0.8 & 0.5 & 95.4 \\
\hline
\end{tabular}

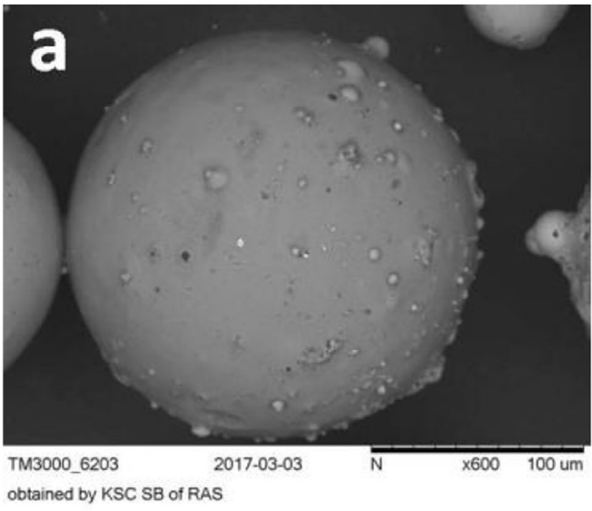

Fig. 1. SEM images of the initial CFAC material: (a) CFAC globule; (b) cross-section of the CFAC wall.

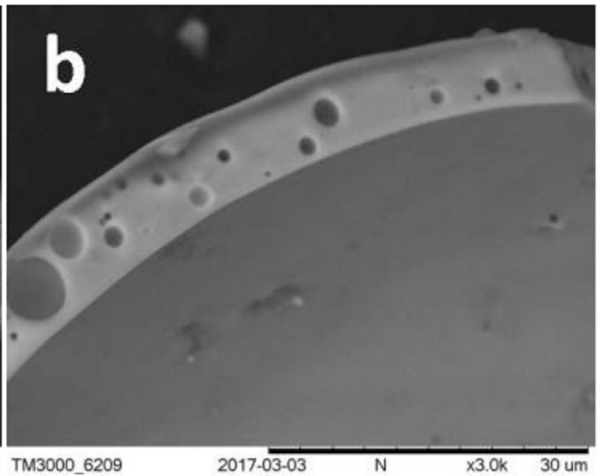

btained by KSC SB of RAS (a)

followed by the deposition of a platinum layer of $\sim 20 \mathrm{~nm}$ thickness. Analysis was carried out at an accelerated voltage of $15 \mathrm{kV}$ in a mapping mode. The data accumulation time was $10 \mathrm{~min}$.

Thermal analysis was performed on a STA Jupiter 449C device (Netzsch, Germany) under a dynamic argon-oxygen atmosphere $\left(20 \% \mathrm{O}_{2}, 50 \mathrm{~mL} / \mathrm{min}\right.$ total flow rate). Platinum crucible with perforated lids was used and the sample mass taken for the measurement was $16.6 \mathrm{mg}$. The measurement procedure consisted of a temperature stabilization segment $\left(30 \mathrm{~min}\right.$ at $40^{\circ} \mathrm{C}$ ) and a dynamic segment at a heating rate of $10^{\circ} / \mathrm{min}$.

The particle size distribution was determined by measuring the average diameter of particles with the use of "Msphere" software as it was reported earlier [29]. Digital images were obtained in reflected and transmitted light on a Carl Zeiss Axioskop 40 (Germany) optical microscope equipped with a Zeiss W-PI 10x/23 eyepiece and a Canon PowerShot A640 digital camera. The diameter was determined for each globule from the digital images processed with "Msphere" software. Statistical data on particle's diameters were obtained based on the analysis of 5364 images.

Chemical composition and element states were determined by $\mathrm{X}$-ray photoelectron spectroscopy using a spectrometer SPECS (Germany) equipped with a PHOIBOS 150 MCD9 electron energy analyzer when exciting X-ray tube by $\mathrm{Mg} \mathrm{K}_{\alpha}$ radiation. The analyzer transmission energy was $20 \mathrm{eV}$ for summarizing spectra and $8 \mathrm{eV}$ for individual scans. Powdered samples were immobilized at a twosided sticky carbon tape. Vacuum in an analytical chamber was not worse than $1 \cdot 10^{-9}$ mbar. Correction for the electrostatic recharging of samples was introduced taking into account the position of C1s line (binding energy is $285.0 \mathrm{eV}$ ) arising from the layer of hydrocarbon contaminations. To eliminate the recharging heterogeneity, treatment with low electrons was applied. Spectra were processed by SpecsLab and CasaXPS software. The reference material was $\mathrm{ZrO}_{2}$ prepared according to Trens et al. [33].

\section{Results and discussion}

According to SEM data, solids produced as a result of the $\mathrm{Zr}$ free and $\mathrm{Zr}$ involving syntheses are differed by the particles morphology and size distribution as well as the degree of conversion of the CFAC material. Another peculiarity of the syntheses is the product outputs differing by two times. The low output in the $\mathrm{Zr}$ bearing reaction mixture can be a result of a colloid state of a considerable part of aluminosilicate which is hardly separated from a liquid phase.

The general feature of the syntheses is that zeolite analcime was the single zeolite phase identified in both products by PXRD. The detailed comparison of two analcime bearing products by their morphology, composition and structure are presented in later sections.

\subsection{Morphology and composition of analcime particles}

SEM images of typical particles occurred in different GS fractions of the $\mathrm{Zr}$ free synthesis product are shown in Fig. 2. The main types of particles entering the GS $>224 \mu \mathrm{m}$ and GS $100-224 \mu \mathrm{m}$ fractions are microsphere-like hollow globules and their fragments with partial icositetrahedral crystals of zeolite analcime [2] attached to external and internal surfaces (Fig. 2 a, b). The dimensions of the outside analcime crystals vary in a wide range - from 3 to $5 \mu \mathrm{m}$ to $30-50 \mu \mathrm{m}$, the smaller analcime particles of $1-10 \mu \mathrm{m}$ being located inside the broken microspheres. The content of the intact analcime bearing globules is considerably lower in the GS 71-100 $\mu \mathrm{m}$ and GS 36-71 $\mu \mathrm{m}$ fractions which include predominantly fragments of broken CFAC with attached analcime crystals, agglomerates of semi-crystals and twinned crystals (Fig. 2 c). The single analcime particles of less than $36 \mu \mathrm{m}$ get together in the GS $<36 \mu \mathrm{m}$ fraction (Fig. 2 d) but their content is rather small and does not exceed $2.2 \mathrm{wt} \%$.

Thus, based on the SEM observation one can conclude that under conditions of synthesis the growth of analcime crystals takes place preferably at the CFAC surface.

The SEM-EDS of the analcime crystals gave an atomic ratio of about $1.1 \mathrm{Na} / 1.9 \mathrm{Si} / 1.0 \mathrm{Al}$ within the range of the $\mathrm{Si} / \mathrm{Al}$ ratio of the zeolite analcime [1].

As for the $\mathrm{Zr}$ involving synthesis, the SEM study of $\mathrm{Zr}$-WS and $\mathrm{Zr}$ GS products has shown that the Zr-WS product includes only particles of a tetragon-trioctahedron habit being typical of zeolite analcime crystals (Fig. 3 a, b) [2]. All the crystals can be 

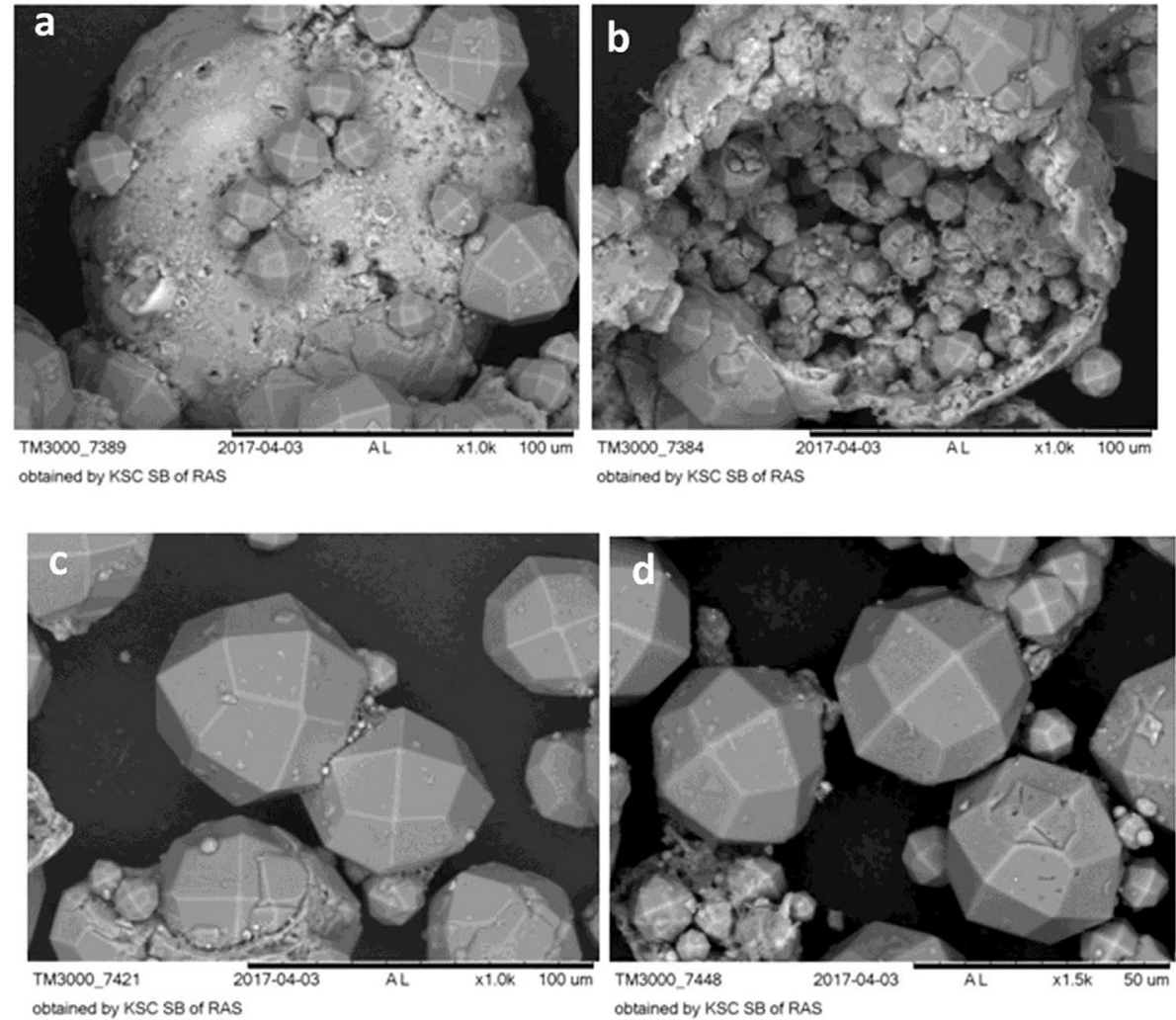

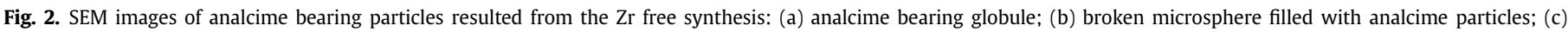
twinned analcime crystal; (d) single analcime crystals.

characterized as icositetrahedra (211) with 24 identical facets of a cubic symmetry which belongs to the cubic $m 3 m$ point group [34].

Analcime-bearing CFAC globules were revealed in the fraction Zr-GS $>71 \mu \mathrm{m}$ (Fig. $3 \mathrm{c}$ ) giving rise to analcime semi-icositetrahedra having an attached piece of the mother CFAC material in its base (Fig. 3 d). The halved analcime particles are concentrated in the fraction $\mathrm{Zr}-\mathrm{WS}<36 \mu \mathrm{m}$ and fractions $\mathrm{Zr}-\mathrm{GS}$ (Zr-GS 36-71 $\mu \mathrm{m}$; Zr-GS $<36 \mu \mathrm{m}$ ), the later ones being enriched in partially dissolved CFAC glass fragments. It can be supposed that the presence of the halved analcime particles together with analcime crystals of a perfect intact morphology would be due to two routes of analcime formation, such as the crystal growth both in the reaction solution and on the CFAC surface. The hydrolyzed forms of zirconium salt occurring in the alkaline reaction mixture are likely to be the primary nuclei of crystallization.

As shown in Fig. 4, the intact analcime particles are characterized by the narrow size distribution with maximum at $41 \mu \mathrm{m}$. Analcime crystals with dimensions of $38-43 \mu \mathrm{m}$ predominate in the $\mathrm{Zr}$-WS product with their content of about $70 \%$ and are the main part of the fraction $\mathrm{Zr}$-WS $36-71 \mu \mathrm{m}$. Particles measuring more than $71 \mu \mathrm{m}$ were not found. The fraction $\mathrm{Zr}-\mathrm{WS}<36 \mu \mathrm{m}$ consists of 19-36 $\mu \mathrm{m}$ particles, among them both intact icositetrahedra and semi-icositetrahedra were detected. It can be proposed that formation of large analcime crystals of the narrow particle size distribution in the presence of hydrolyzed $\mathrm{Zr}$ forms are controlled by the ratio of two parameters, such as the release rate of silicate and aluminate species by dissolution of CFAC glass and the rate of crystal growth on the $\mathrm{Zr}$ species achieved under the reaction conditions.

The SEM-EDS of polished cross-sections of individual analcime particles gave an atomic ratio of about $1.0 \mathrm{Na} / 2.1 \mathrm{Si} / 1.0 \mathrm{Al}$ which is close to that of the $\mathrm{Zr}$ free analcime. The presence of $\mathrm{Zr}$ matter inclusions in the bulk of the analcime crystals is supported by the SEM-EDS measurements of local concentrations of elements over analcime crystal cross-sections which are differed by the $\mathrm{Zr}$ content (Fig. 5a, Table 2, Fig. S1). Zirconium species are visible as contrast white spots on facets of analcime icositetrahedra, surfaces of all analcime bearing particles and in the bulk of crystals (Figs. 3 and 5). The average $\mathrm{Zr}$ content in the analcime particles was about $4.8 \mathrm{wt} \%$.

According to the XPS data, the local charges of $\mathrm{Zr}$ atoms found in the analcime crystals ( $\mathrm{Zr}-\mathrm{WS} 36-71 \mu \mathrm{m}$ ) and $\mathrm{Zr}$ atoms being part of zirconia are close (Fig. 6) indicating that the most probable state of zirconium occurred in the $\mathrm{Zr}$ bearing analcime (Zr-ANA) is zirconia.

As shown in Fig. 7, the thermal conversion of $\mathrm{Zr}$ free analcime particles (GS 100-224 $\mu \mathrm{m}$ ) includes two stages. The first broad endothermic DSC peak with the substantial mass loss is situated at $100-460{ }^{\circ} \mathrm{C}\left(\mathrm{T}_{\mathrm{m}}=365{ }^{\circ} \mathrm{C}\right.$, total mass loss $\left.\Delta \mathrm{m}=8.06 \mathrm{wt} \%\right)$ and is accompanied by the parallel increase of intensity of $\mathrm{m} / \mathrm{z}=18\left(\mathrm{H}_{2} \mathrm{O}\right)$ ion due to water elimination. An incomplete cenosphere-toanalcime transformation is a reason for a reduced mass loss compared to the theoretical water content of $8.17 \mathrm{wt} \%$. The second exothermic peak is observed at $790-880{ }^{\circ} \mathrm{C}\left(\mathrm{T}_{\mathrm{m}}=797{ }^{\circ} \mathrm{C}\right)$. The absence of mass change at this temperature interval suggests that the exo-effect is caused by the solid state transformation (re-crystallization) of analcime. A similar temperature interval of water elimination is observed for $\mathrm{Zr}$-analcime ( $\mathrm{Zr}$-WS 36-71 $\mu \mathrm{m}$ ), the $\mathrm{Zr}$ species inclusions in the analcime crystals can be a reason for a reduced mass loss $(\Delta \mathrm{m}=7.87 \mathrm{wt} \%)$. There was no pronounced exothermic effect found at $797{ }^{\circ} \mathrm{C}$ but the PXRD analysis of $\mathrm{Zr}$ analcime calcined at $900{ }^{\circ} \mathrm{C}$ revealed $\mathrm{ZrO}_{2}$ and nepheline phases in the calcination product (Fig. S2) so the observed broad peak at 

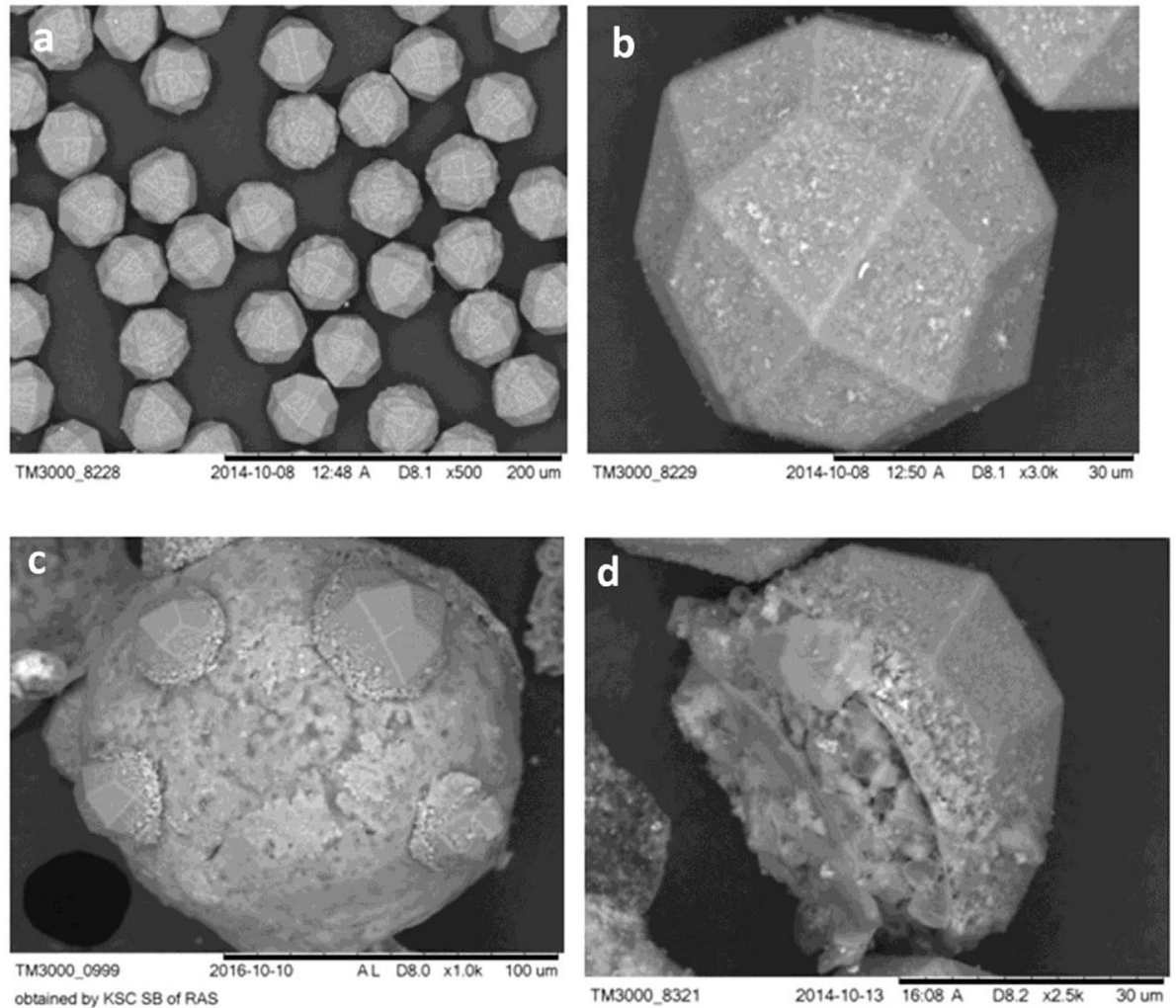

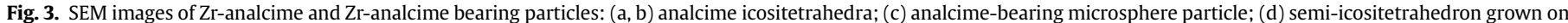
the CFAC surface.

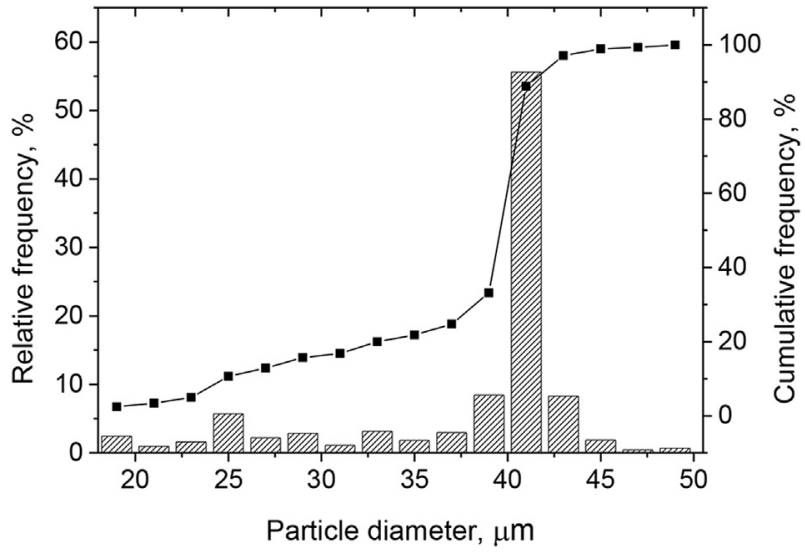

Fig. 4. Particle size distribution for analcime fraction $\mathrm{Zr}-\mathrm{WS}$. about $800-840{ }^{\circ} \mathrm{C}$ can be also assigned to the $\mathrm{Zr}$-analcime recrystallization.

\subsection{Crystal structure of analcime and Zr-analcime}

In order to assess the influence of $\mathrm{Zr}$ on the structural characteristics of analcime phase crystallized in its presence, a full-profile PXRD crystal structure analysis was carried out for both pristine and zirconia-incorporated analcime samples. It should be noted that detailed and reliable PXRD analysis of analcime crystal structure and composition presents a challenging task. The cations, vacant sites and water molecules in an approximately cubic crystal lattice of analcime are distributed statistically, giving rise to local symmetry variations and distortions (displacements) of atomic positions. Refinement of such crystal structures requires a complete model including the anisotropic displacement parameters of all
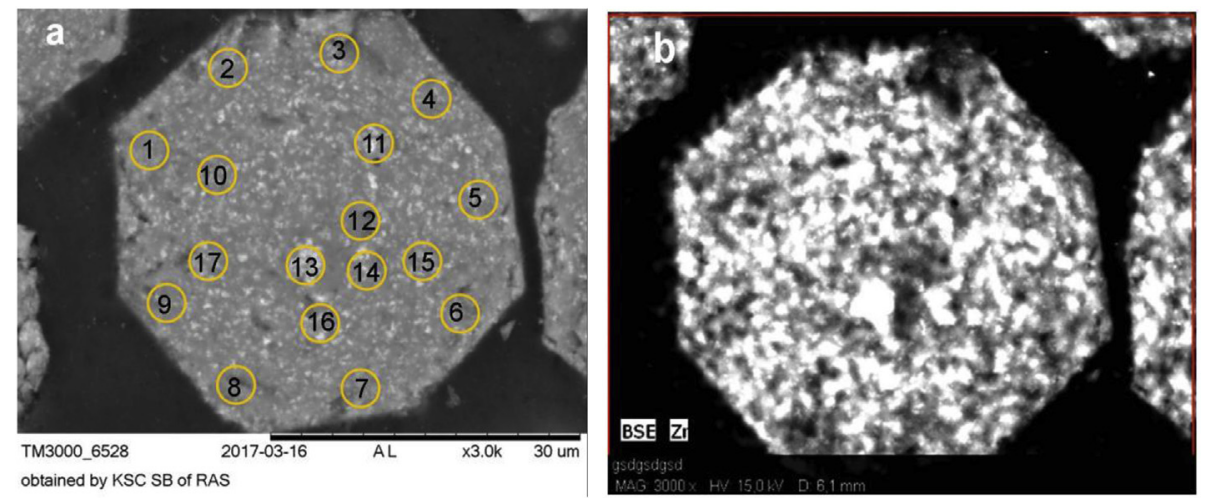

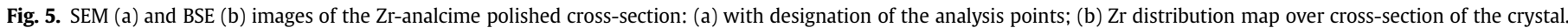


Table 2

Local elemental composition of $\mathrm{Zr}$-analcime particles according to the SEM-EDS data.

\begin{tabular}{llllll}
\hline No.* & \multicolumn{3}{l}{ Content, wt\% } & & \\
\cline { 2 - 5 } & $\mathrm{O}$ & $\mathrm{Si}$ & $\mathrm{Al}$ & $\mathrm{Na}$ & $\mathrm{Zr}$ \\
\hline 1 & 49.0 & 25.0 & 11.7 & 11.4 & 2.9 \\
2 & 47.7 & 24.3 & 11.8 & 10.4 & 5.8 \\
3 & 47.9 & 26.6 & 11.0 & 10.1 & 4.4 \\
4 & 46.9 & 26.7 & 12.5 & 9.5 & 4.4 \\
5 & 46.3 & 26.2 & 12.4 & 10.0 & 5.1 \\
6 & 44.2 & 26.8 & 13.3 & 9.5 & 6.2 \\
7 & 50.4 & 24.0 & 11.8 & 10.0 & 3.8 \\
8 & 47.6 & 26.8 & 13.1 & 10.4 & 2.1 \\
9 & 50.8 & 23.8 & 11.5 & 11.1 & 2.8 \\
10 & 48.5 & 25.1 & 11.6 & 9.9 & 4.9 \\
11 & 47.9 & 25.9 & 11.7 & 9.4 & 5.1 \\
12 & 49.3 & 26.0 & 12.5 & 9.3 & 2.9 \\
13 & 46.2 & 25.4 & 10.9 & 9.4 & 8.1 \\
14 & 47.3 & 26.8 & 11.2 & 9.1 & 5.6 \\
15 & 47.5 & 27.2 & 11.0 & 9.2 & 5.1 \\
16 & 46.7 & 26.4 & 11.2 & 9.5 & 6.2 \\
17 & 49.1 & 26.4 & 10.8 & 9.1 & 4.6 \\
\hline
\end{tabular}

* As in Fig. 5a. atoms and precise $\mathrm{H}$-positions related to water. The anisotropic parameters and some hydrogen-related positions for cubic analcime were derived in a single-crystal neutron diffraction study of a mineral analcime [35]. However, as the authors of [35] noted, the resulted $\mathrm{H}$-positions were not realistic since none of the $\mathrm{H}-\mathrm{O}-\mathrm{H}$ and $\mathrm{Na}-\mathrm{O}-\mathrm{H}$ angles accorded reasonably with the normal geometry of the Na-coordinated water molecules. In the present study, complete crystal structures of the analcime samples were refined using the DDM method that has been proven to provide detailed and reliable structural information from powder diffraction data including the anisotropic displacement parameters and positions of H-atoms [36-38].

A comparison of observed and calculated PXRD patterns for both samples is presented in Fig. 8. The refined compositions, lattice parameters and experimental details are summarized in Table 3. The atomic coordinates, site occupancies and anisotropic displacement parameters are available in the crystallographic information files (CIFs) from the supplementary material.

An ellipsoid plot of analcime crystal structure refined by DDM is compared in Fig. 9 with that resulted from the single-crystal neutron diffraction [35]. As seen, the shapes of atomic

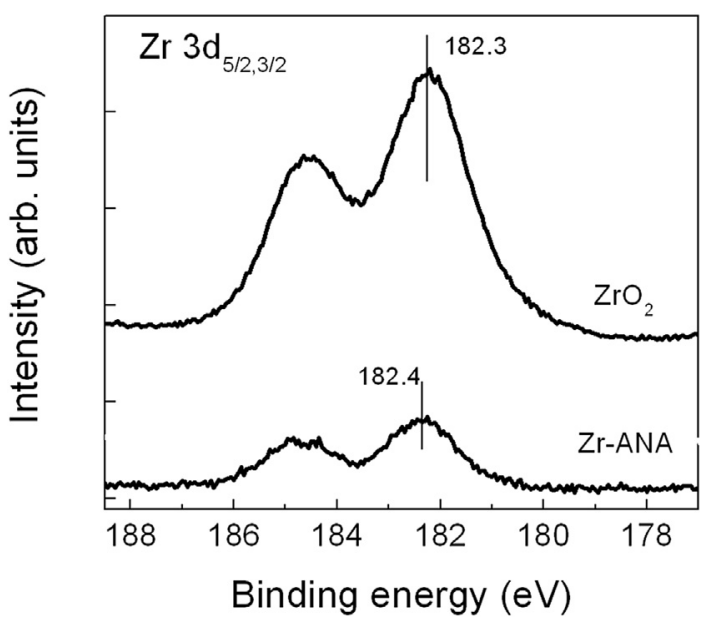

Fig. 6. XPS patterns of $\mathrm{Zr} 3 \mathrm{D}$ doublet in $\mathrm{Zr}$-analcime and zirconia.

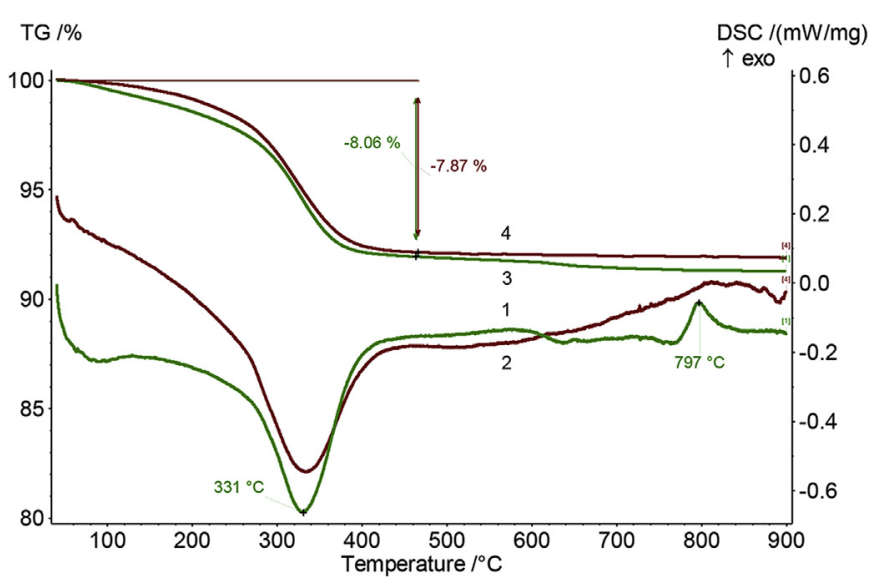

Fig. 7. DSC $(1,2)$ and TG $(3,4)$ curves of the thermal transformation of analcime particles $(1,3)$ and $\mathrm{Zr}$-analcime $(2,4)$ in a dynamic argon-oxygen atmosphere $20 \% \mathrm{O}_{2}$ - $\mathrm{Ar}$, $10^{\circ} / \mathrm{min}$.
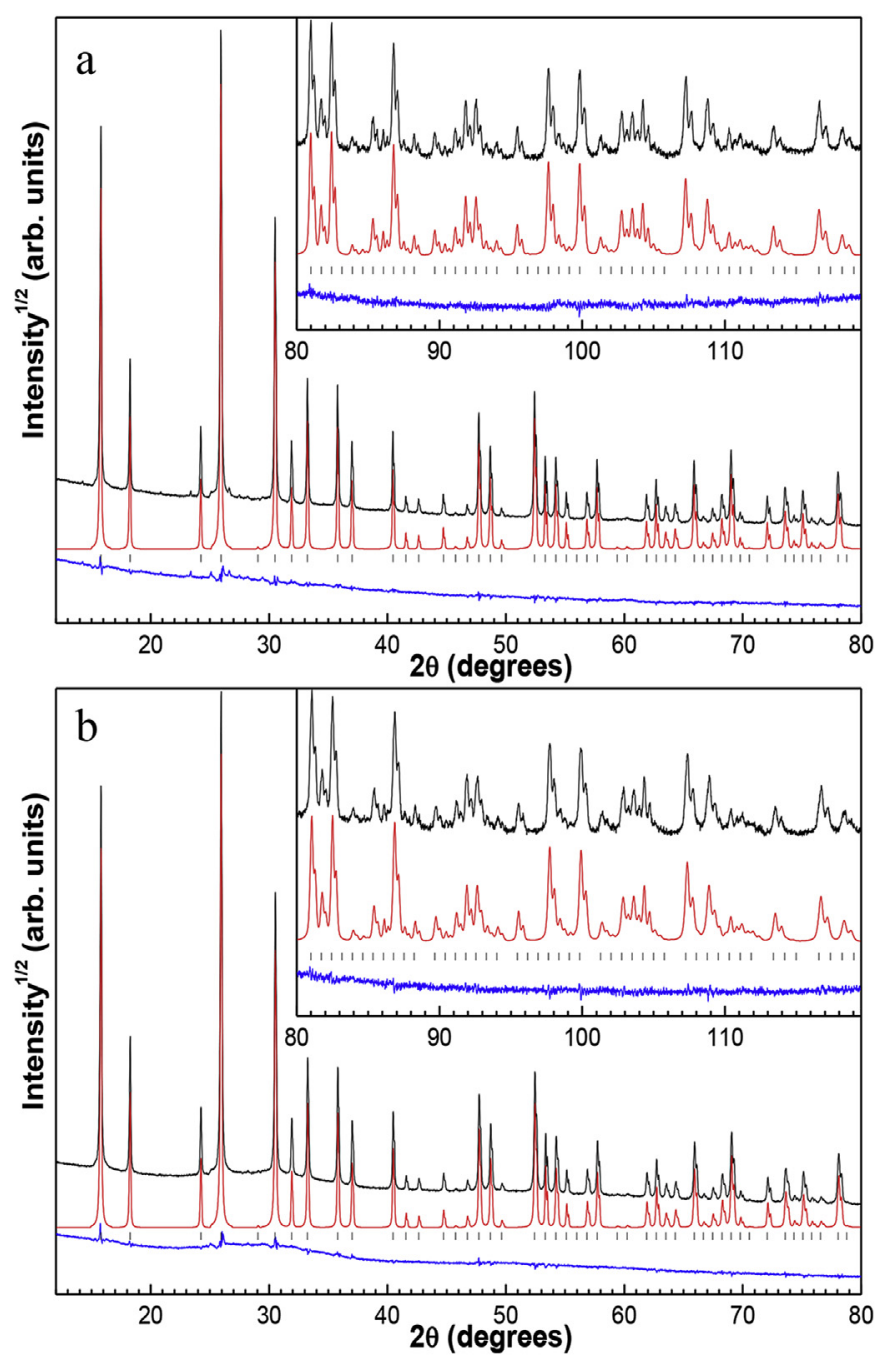

Fig. 8. Observed (top), calculated (mid), and difference (bottom) PXRD profiles after DDM crystal structure refinement of (a) analcime and (b) Zr-analcime. 
Table 3

PXRD experimental details.

\begin{tabular}{|c|c|c|}
\hline & Analcime & Zr-Analcime \\
\hline \multicolumn{3}{|l|}{ Crystal data } \\
\hline Chemical formula & $\mathrm{Na}_{0.986}\left(\mathrm{Al}_{0.986} \mathrm{Si}_{2.014} \mathrm{O}_{6}\right)\left(\mathrm{H}_{2} \mathrm{O}\right)_{0.977}$ & $\mathrm{Na}_{0.95}\left(\mathrm{Al}_{0.95} \mathrm{Si}_{2.05} \mathrm{O}_{6}\right)\left(\mathrm{H}_{2} \mathrm{O}\right)_{0.946}$ \\
\hline Space group & $I a-3 d$ & $I a-3 d$ \\
\hline Lattice parameter $(\AA)$ & $13.7319(4)$ & $13.7219(4)$ \\
\hline$V\left(\AA^{3}\right)$ & $2589.4(2)$ & $2583.7(2)$ \\
\hline$Z$ & 16 & 16 \\
\hline Temperature (K) & 298 & 298 \\
\hline Radiation type & $\mathrm{Cu} \mathrm{K} \alpha$ & $\mathrm{Cu} \mathrm{K} \alpha$ \\
\hline \multicolumn{3}{|l|}{ Refinement } \\
\hline$R$ factors and goodness of fit & $\begin{array}{l}R_{\mathrm{DDM}}=0.056, R_{\exp }=0.021 \\
R_{\mathrm{Bragg}}=0.018, R(F)=0.020 \\
\chi^{2}=2.646\end{array}$ & $\begin{array}{l}R_{\mathrm{DDM}}=0.075, R_{\exp }=0.033 \\
R_{\mathrm{Bragg}}=0.018, R(F)=0.015 \\
\chi^{2}=2.265\end{array}$ \\
\hline
\end{tabular}
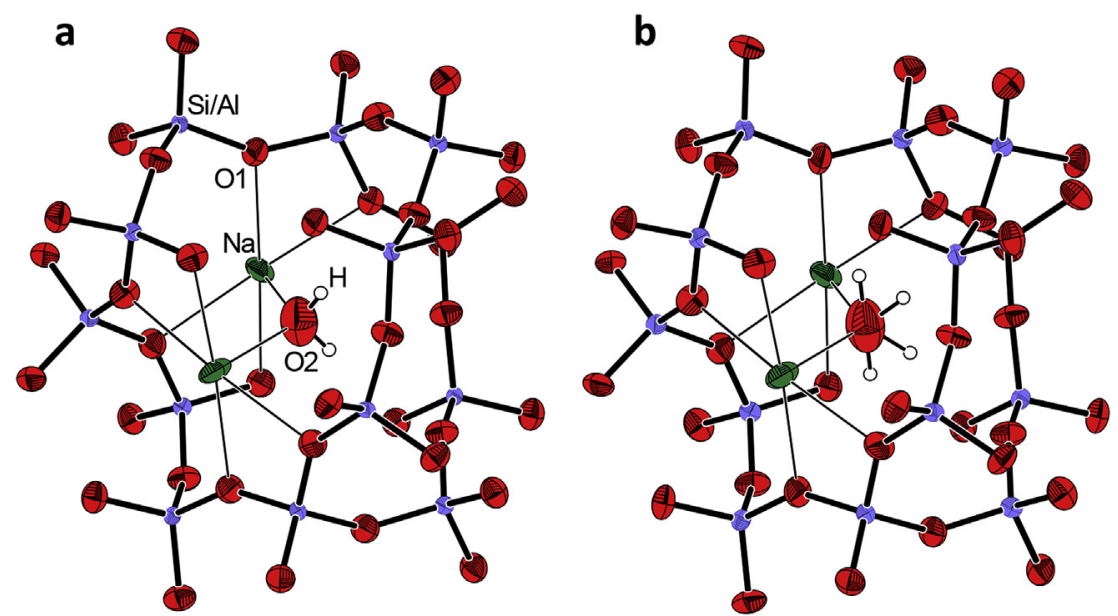

Fig. 9. Ellipsoid plot of analcime crystal structure determined from (a) PXRD and (b) single-crystal neutron diffraction [35].

displacement ellipsoids are perfectly reproduced for both refinements, emphasizing the accuracy of DDM. The ellipsoid plot shows that the water molecules are strongly disordered in the structure, which could be one of the reasons for the problematic location of H-positions in the neutron diffraction investigation [35]. In the DDM analysis, the displacement parameters of hydrogen atom were constrained with those of respective oxygen atom, which allowed a stable free refinement of $\mathrm{H}$-coordinates without geometric restraints and gave reproducibly normal $\mathrm{O}-\mathrm{H}$ distances as well as $\mathrm{H}-\mathrm{O}-\mathrm{H}$ and $\mathrm{Na}-\mathrm{O}-\mathrm{H}$ angles for both samples under investigation (Table 4).

The occupancies of $\mathrm{Na}$ and water sites were refined independently and the Si/Al ratio was determined from the resulted $\mathrm{Na}$ content in the structures giving the values of 2.04 and 2.16 for pristine analcime and $\mathrm{Zr}$-analcime samples, respectively, which were close to those determined by the SEM-EDS (1.9 and 2.1). The revealed difference in the $\mathrm{Si} / \mathrm{Al}$ ratios can be explained by different concentrations of sodium aluminate species in the reaction mixtures formed as a result of dissolution of CFAC aluminosilicate glass with participation of $\mathrm{NaOH}$. In the case of the $\mathrm{Zr}$ involving synthesis, the zirconium salt added into the sodium alkaline solution is hydrolyzed resulting in $\left[\mathrm{ZrO}_{\mathrm{x}}(\mathrm{OH})_{4-2 \mathrm{x}} \cdot \mathrm{yH}_{2} \mathrm{O}\right]_{\mathrm{n}}$ [39] and decreasing the concentration of active $\mathrm{OH}^{-}$groups and, accordingly, $\mathrm{NaAlO}_{2}$. The change of $\mathrm{NaAlO}_{2}$ content in the alkaline solution of the lower $\mathrm{NaOH}$ concentration can be due also to kinetic factors of dissolution of CFAC glass which is inhomogeneous in chemical composition and contains regions enriched in $\mathrm{Si}, \mathrm{Al}$ or other elements [40].
Table 4

Selected geometric parameters of analcime structure $\left(\AA,^{\circ}\right)$.

\begin{tabular}{llll}
\hline Analcime & & & \\
$\mathrm{Si}-\mathrm{O} 1$ & $1.6439(5)$ & $\mathrm{Na}-\mathrm{O} 2$ & $2.4275(1)$ \\
$\mathrm{Si}-\mathrm{O} 1^{\mathrm{i}}$ & $1.6411(5)$ & $\mathrm{O} 2-\mathrm{H}$ & $0.85(5)$ \\
$\mathrm{Na}-\mathrm{O} 1$ & $2.5186(5)$ & & \\
$\mathrm{O} 1-\mathrm{Si}-\mathrm{O} 1^{\mathrm{ii}}$ & $105.20(4)$ & $\mathrm{O} 1-\mathrm{Na}-\mathrm{O} 1^{\mathrm{v}}$ & $174.89(2)$ \\
$\mathrm{O} 1-\mathrm{Si}-\mathrm{O} 1^{\mathrm{i}}$ & $111.20(2)$ & $\mathrm{O} 1-\mathrm{Na}-\mathrm{O} 2$ & $92.553(11)$ \\
$\mathrm{O} 1-\mathrm{Si}-\mathrm{O} 1^{\mathrm{iii}}$ & $111.14(3)$ & $\mathrm{O} 1-\mathrm{Na}-\mathrm{O} 2^{\mathrm{vi}}$ & $87.447(11)$ \\
$\mathrm{O} 1^{\mathrm{i}}-\mathrm{Si}-\mathrm{O} 1^{\mathrm{ii}}$ & $107.03(4)$ & $\mathrm{Na}-\mathrm{O} 2-\mathrm{H}^{\mathrm{vii}}$ & $105(4)$ \\
$\mathrm{O} 1-\mathrm{Na}-\mathrm{O} 1^{\mathrm{ii}}$ & $62.46(2)$ & $\mathrm{Na}-\mathrm{O} 2-\mathrm{H}^{\mathrm{vii}}$ & $112(4)$ \\
$\mathrm{O} 1-\mathrm{Na}-\mathrm{O} 1^{\mathrm{iv}}$ & $117.79(2)$ & $\mathrm{H}-\mathrm{O}-\mathrm{H}^{\mathrm{v}}$ & $102(7)$ \\
\hline $\mathrm{Zr}-\mathrm{Analcime}$ & & & \\
$\mathrm{Si}-\mathrm{O} 1$ & $1.6421(4)$ & $\mathrm{Na}-\mathrm{O} 2$ & $2.4257(1)$ \\
$\mathrm{Si}-\mathrm{O} 1^{\mathrm{i}}$ & $1.6394(4)$ & $\mathrm{O} 2-\mathrm{H}$ & $0.86(3)$ \\
$\mathrm{Na}-\mathrm{O} 1$ & $2.5187(4)$ & & $174.972(17)$ \\
$\mathrm{O} 1-\mathrm{Si}-\mathrm{O} 1^{\mathrm{ii}}$ & $105.30(3)$ & $\mathrm{O} 1-\mathrm{Na}-\mathrm{O} 1^{\mathrm{v}}$ & $92.514(8)$ \\
$\mathrm{O} 1-\mathrm{Si}-\mathrm{O} 1^{\mathrm{i}}$ & $111.160(17)$ & $\mathrm{O} 1-\mathrm{Na}-\mathrm{O} 2$ & $87.486(8)$ \\
$\mathrm{O} 1-\mathrm{Si}-\mathrm{O} 1^{\mathrm{iii}}$ & $111.03(2)$ & $\mathrm{O} 1-\mathrm{Na}-\mathrm{O} 2^{\mathrm{vi}}$ & $113(3)$ \\
$\mathrm{O} 1^{\mathrm{i}}-\mathrm{Si}-\mathrm{O} 1^{\mathrm{iii}}$ & $107.23(3)$ & $\mathrm{Na}-\mathrm{O} 2-\mathrm{H}^{\mathrm{vii}}$ & $102(3)$ \\
$\mathrm{O} 1-\mathrm{Na}-\mathrm{O} 1^{\mathrm{ii}}$ & $62.434(18)$ & $\mathrm{Na}-\mathrm{O} 2-\mathrm{H}^{\mathrm{vii}}$ & $105(5)$ \\
$\mathrm{O} 1-\mathrm{Na}-\mathrm{O} 1^{\text {iv }}$ & $117.815(18)$ & $\mathrm{H}-\mathrm{O} 2-\mathrm{H}^{\mathrm{v}}$ & \\
\hline
\end{tabular}

Symmetry codes: (i) $z-1 / 4,-y+1 / 4,-x+3 / 4$; (ii) $-x+1 / 4, z-1 / 4, y+1 / 4$; (iii) $-z+1 / 2$, $-x+1 / 2,-y+1 / 2$; (iv) $x,-y,-z+1 / 2$; (v) $-x+1 / 4,-z+1 / 4,-y+1 / 4$; (vi) $-y+1 / 4, x-1 / 4, z+1 /$ 4 ; (vii) $y, z, x$; (viii) $z, x, y$.

XRD peaks of $\mathrm{ZrO}_{2}$ were not observed for the analcime-zirconia composite. A broad amorphous scattering between 20 and $40^{\circ}$ 2Theta in Fig. 8b suggests that $\mathrm{ZrO}_{2}$ is essentially amorphous in the sample. 
Thus, as it is shown by the detailed PXRD analysis, the crystal structures and compositions of analcime resulted from both syntheses are close with a minor variation in the $\mathrm{Si} / \mathrm{Al}$ ratio.

\section{Conclusions}

For the first time, analcime of a cubic structure with the $\mathrm{Si} / \mathrm{Al}$ ratio of around 2.0 was synthesized as a single zeolite phase under hydrothermal conditions at $150{ }^{\circ} \mathrm{C}$ starting from CFAC with $\mathrm{Si} /$ $\mathrm{Al}=2.7$ as a $\mathrm{Si}$ and $\mathrm{Al}$ source. The microsphere particles with attached analcime crystals of $5-50 \mu \mathrm{m}$ in size are the main product of the synthesis. In the presence of zirconium salt, analcime icositetrahedral crystallites with the Si/Al ratio of 2.16 and $\mathrm{Zr}$ content of $4.8 \mathrm{wt} \%$ are generated. Growth of identical $\mathrm{Zr}$-analcime crystals with the narrow particle size distribution $\left(D_{m}=41 \mu \mathrm{m}\right)$ takes place in the bulk of the reaction mixture and is likely to be controlled by the ratio of two parameters achieved under the reaction conditions, such as the release rate of silicate and aluminate species by dissolution of CFAC glass and the rate of crystal growth with participation of hydrolyzed $\mathrm{Zr}$ species which do not affect the zeolite topology but promote nucleation of zeolite. The crystal structures and compositions of analcime resulted from both syntheses are close with a minor variation in the $\mathrm{Si} / \mathrm{Al}$ ratio. $\mathrm{Zr}$ atoms do not enter the zeolite structure as T-atoms or extra-framework cations but are the part of zirconia captured by the analcime crystals in the process of their growth. Refinement of complete crystal structures of the analcime samples using the DDM method provided detailed and reliable structural information from powder diffraction data including the anisotropic displacement parameters and positions of $\mathrm{H}$-atoms.

The proposed sustainable approach to the synthesis of analcime based materials favours their application in different industrial fields, first of all, as sorbents of actinides and mineral-like matrices of ANA topology in ${ }^{137}$ Cs nuclear waste disposal.

\section{Acknowledgements}

The work was supported by the State budget allocated to the fundamental research in the Russian Academy of Sciences in the framework of Project No. V.45.3.3. The authors acknowledge Dr. A. M. Zhizhaev for preparation and SEM-EDS examination of analcime polished cross-sections and Dr. Yu. L. Mikhlin for XPS measurement.

\section{Appendix A. Supplementary data}

Supplementary data related to this article can be found at https://doi.org/10.1016/j.micromeso.2017.09.011.

\section{References}

[1] D.W. Breck, Zeolite Molecular Sieves: Structure, Chemistry, and Use, John Wiley \& Sons, New York, 1974.

[2] W.S. Wise, Handbook of Natural Zeolites, in: C. Colella (Ed.), Internationa Zeolite Association, Natural Zeolites Commission, Napoli, Italy, 2013. A. De Frede Edotore : Natural Zeolites Commission.
[3] W.D. Balgord, R. Roy, Molecular Sieve Zeolites-1 Advances in Chemistry, 101, American Chemical Society, Washington, DC, 1971.

[4] S.H. Paek, C.D. Chung, G. Seo, Micropor. Mesopor. Mater. 155 (2012) 201-207.

[5] J.-N. Fang, I.-C. Lin, H.-J. Lo, S.-R. Song, Y.-L. Chen, J. Chin. Chem. Soc. 51 (2004) $1267-1272$.

[6] Y. Wang, X. Li, Z. Xue, L. Dai, S. Xie, Q. Li, J. Phys. Chem. B 114 (2010) 5747-5754.

[7] B.S. Liu, C.T. Au, Chem. Lett. 31 (2002) 806-807.

[8] A. Bejar, S.B. Chaabene, M. Jaber, J.-F. Lambert, L. Bergaoui, Micropor. Mesopor. Mater. 196 (2014) 158-164.

[9] E.Z. Hegazy, I.H. Abd El Maksod, R.M.M. Abo El Enin, Appl. Clay Sci. 49 (2010) 149-155.

[10] N.G. Rachkova, A.I. Taskaev, Radiochemistry 53 (2011) 314-321.

[11] H. Mimura, M. Shibata, K. Akiba, J. Nucl. Sci. Technol. 27 (1990) 167-173.

[12] Z. Jing, K. Cai, Y. Li, J. Fan, Y. Zhang, J. Miao, Y. Chen, F. Jin, J. Nucl. Mater. 488 (2017) 63-69.

[13] J. Fan, Z. Jing, Y. Zhang, J. Miao, Y. Chen, F. Jin, Chem. Eng. J. 304 (2016) $344-350$.

[14] A.F. Redkin, J.J. Hemley, Eur. J. Mineral. 12 (2000) 999-1014.

[15] M.A. Subramanian, D.R. Corbin, U. Chowdhry, Bul. Mat. Sci. 16 (1993) 665-678.

[16] A. Marocco, G. Dell'Agli, S. Esposito, M. Pansini, Solid State Sci. 14 (2012) $394-400$.

[17] E.R. Begley, P.O. Herndon, Refract. Mater. 5 (1971) 185-208.

[18] I.W. Donald, Waste Immobilization in Glass and Ceramic Based Hosts: Radioactive, Toxic and Hazardous Wastes, John Wiley \& Sons, Wiley-Blackwell Chichester, 2010.

[19] R.M. Barrer, Hydrothermal Chemistry of Zeolites, Academic Press, New York, 1982.

[20] (a) X. Querol, N. Moreno, J.C. Urnana, A. Alastuey, E. Hernandez, A. Lopez Soler, F. Plana, Int. J. Coal Geol. 50 (2002) 413-423;

(b) L. Zhou, Y.-L. Chen, X.-H. Zhang, F.-M. Tian, Z.-N. Zu, Mater. Lett. 119 (2014) $140-142$.

[21] M.V. Sandoval, J.A. Henao, C.A. Rios, C.D. Williams, D.C. Apperley, Fuel 88 (2009) 272-281.

[22] D. Ma, Y. Shu, X. Han, X. Liu, Y. Xu, X. Bao, J. Phys. Chem. B 105 (2001) 1786-1793.

[23] A. Dyer, S. Tangkawanit, K. Rangsriwatananon, Micropor. Mesopor. Mater. 75 (2004) 273-279.

[24] T.A. Vereshchagina, S.N. Vereshchagin, N.N. Shishkina, L.A. Solovyov, N.G. Vasilieva, A.G. Anshits, J. Nucl. Mater. 437 (2013) 11-18.

[25] S.N. Vereshchagin, T.A. Vereshchagina, N.N. Shishkina, A.G. Anshits, Chem. Sustain. Devel 16 (2008) 511-519 (Transl. Khim. Interesakh Ustoich. Razvit.).

[26] T.A. Vereshchagina, S.N. Vereshchagin, N.N. Shishkina, L.A. Solovyov, O.A. Mikhaylova, A.G. Anshits, Micropor. Mesopor. Mater. 169 (2013) 207-211.

[27] N.N. Anshits, O.A. Mikhailova, A.N. Salanov, A.G. Anshits, Fuel 89 (2010) 1849-1862.

[28] E.V. Fomenko, N.N. Anshits, L.A. Solovyov, O.A. Mikhaylova, A.G. Anshits, Energy fuels 27 (2013) 5440-5448.

[29] E.V. Fomenko, N.N. Anshits, N.G. Vasil'eva, E.S. Rogovenko, O.A. Mikhaylova, E.V. Mazurova, L.A. Solovyev, A.G. Anshits, Solid Fuel Chem. 50 (2016) $238-247$.

[30] Cements and materials for cement production, Chemical Analysis Methods, State Standard (GOST) No.5382-91, IPK Izdatel'stvo standartov, Moscow, 2002.

[31] H. Rietveld, J. Appl. Crystallogr. 2 (1969) 65-71.

[32] L.A. Solovyov, J. Appl. Crystallogr. 37 (2004) 743-749.

[33] P. Trens, M.J. Hudson, R. Denoyel, J. Mater. Chem. 8 (1998) 2147-2152.

[34] V. Pecharsky, P. Zavalij, Fundamentals of Powder Diffraction and Structural Characterization of Materials, second ed., Springer, US, 2009.

[35] G. Ferraris, D.W. Jones, J. Jerkess, Z. Krist. 135 (1972) 240-252.

[36] L.A. Solovyov, Acta Crystallogr. B72 (2016) 738-743.

[37] L.A. Solovyov, Acta Crystallogr. B68 (2012) 89-90.

[38] L.A. Solovyov, A.M. Astachov, M.S. Molokeev, A.D. Vasiliev, Acta Crystallogr. B61 (2005) 435-442.

[39] A. Clearfield, G.P.D. Serrette, A.H. Khazi-Syed, Catal. Today 20 (1994) 295-312.

[40] E.V. Fomenko, N.N. Anshits, N.G. Vasilieva, O.A. Mikhaylova, E.S. Rogovenko, A.M. Zhizhaev, A.G. Anshits, Energy fuels 29 (2015) 5390-5403. 